\title{
The Potential Role of Psychiatry Residents' Councils
}

\author{
J. Thomas Pichot, MD \\ Eisenhower Army Medical Center, Fort Gordon Georgia
}

Follow this and additional works at: https://jdc.jefferson.edu/jeffjpsychiatry

Part of the Psychiatry Commons

Let us know how access to this document benefits you

\section{Recommended Citation}

Pichot, MD, J. Thomas (1988) "The Potential Role of Psychiatry Residents' Councils," Jefferson Journal of Psychiatry. Vol. 6 : Iss. 2 , Article 5.

DOI: https://doi.org/10.29046/JJP.006.2.003

Available at: https://jdc.jefferson.edu/jeffjpsychiatry/vol6/iss2/5

This Article is brought to you for free and open access by the Jefferson Digital Commons. The Jefferson Digital Commons is a service of Thomas Jefferson University's Center for Teaching and Learning (CTL). The Commons is a showcase for Jefferson books and journals, peer-reviewed scholarly publications, unique historical collections from the University archives, and teaching tools. The Jefferson Digital Commons allows researchers and interested readers anywhere in the world to learn about and keep up to date with Jefferson scholarship. This article has been accepted for inclusion in Jefferson Journal of Psychiatry by an authorized administrator of the Jefferson Digital Commons. For more information, please contact: JeffersonDigitalCommons@jefferson.edu. 


\title{
The Potential Role for Psychiatry Residents' Councils
}

\author{
J. Thomas Pichot, M.D.
}

There are numerous books and articles within the scientific literature that deal with issues of training psychiatry residents and the characteristics of that milieu. Those authors that deal primarily with stress usually discuss the sources of the stress and the resultant behavioral changes that are manifested by the trainees. Typically, a relatively small portion of the discussion is devoted to how these problems are, or might be, addressed. This paper, while not itself intended to be an overview of stress in residency; will concentrate on a literature review of some specific aspects of the residency training process, primarily role definition and identity formation. There is also a review of some common, and some more unique, ways to attempt to help residents avoid maladaptive responses to training milieu stressors. The last section of the article will look at how a residents' organizational group (residents' council) might function to help facilitate the identity formation in a more adaptive manner and possibly help to alleviate some negative responses that are commonly observed in trainees.

\section{STRESS IN RESIDENCY TRAINING}

The stress inherent to the milieu of psychiatric training has been discussed in numerous contexts (1-42). Reviewing the aggregate bibliographies of these papers shows that few articles addressed this issue prior to 1965 , but that between 1965 and the mid-1970's there was a tremendous increase in the number of papers that dealt with stress in the psychiatric training process. These issues were discussed in two significant separate papers written by Joel Yager (1) and John Graves (2) that were published in the mid-1970's. Both authors considered separation/individuation, identity formation, and role definition as key aspects in the development of a psychiatrist. Dr. Yager addressed the concept of "overchoice", referring to the situation that faces the beginning resident when he is given the task of patient care prior to having a framework to utilize. In attempting to develop such a framework the resident is faced with a multitude of theories, techniques, and concepts from which to choose (1). Along these lines, Graves noted the transition from the medical model to the less structured psychiatric model of patient care as a source of anxiety for many beginning residents (2). Graves further clarified the problems with professional identity formation by discussing the multitude of roles in which the resident 
must function. Within a matter of hours the resident is switching "back and forth between the roles of therapist, patient, student, seminar leader, parent and peer". Furthermore, Dr. Graves notes that such rapid transitions can be as "awkward, confusing and as anxiety provoking as the child pendulum swings in adolescence". However, he also acknowledges that some degree of identity crisis is unavoidable, necessary and indeed, desirable in the process of forming one's professional identity (2).

A paper written in 1981 by Garfinkel and Waring (3), noted some factors common to all postgraduate medical training, such as prolonged dependency, hostility engendered by competition, and relative socio-economic difficulties in comparison with non-training peers. Additionally, the authors point out some factors specific to psychiatric training, including: 1) identification with the psychopathology of one's patients, 2) the impact of psychotherapy supervision and the associated development of psychological mindedness, and 3) the shift from the authoritarian role of the physician to the interdisciplinary team approach of clinical psychiatry (3). Military training programs may have some unique additional stresses, recently reviewed in an article by Hales (4).

Adapting Levinson's (5) theoretical framework of male adult development, the majority of residents fall in the Era of Early Adulthood and more specifically, the Middle Period of the Age 30 Transition. This transition period falls between the ages of 26 to 34, and according to Levinson, typically lasts four to five years. The basic life structure is always different at the end of the Age 30 Transition then it is at the beginning; for some individuals this transition is smooth, "a time of reform, not revolution", but for most of us a moderate to severe crisis is very common during this period (5). Furthermore, the Age 30 crisis is described as a time of revising the first, provisional life structure formed in the preceding stage, a time of reappraising the past and considering the future. An Age 30 transition is not merely a delayed adolescent crisis, (although unresolved conflicts of adolescence will be reactivated and perhaps more fully resolved in it), nor is it a precocious mid-life crisis, (although it has much in common with transitional problems of persons who, at about 40 , feel caught in a life structure that has become intolerable). Actually, it is a crisis which is very characteristic for the developmental issues of that particular period of life (5). Graves addresses these issues in residency training while describing this experience as a period of intense peer identification and notes that it is not unusual to have the feeling that one is reliving late high-school and early college days (2). He further notes that often this leads to feelings that one is playing out and searching for roles suitable for "the real world" or for "when I grow up". However, here again it is noted that this experience is more than a simple reliving and recapitulation of the past; instead, it is "a reworking of personal issues on a professional level from the perspective of some eight to ten years of maturation" (2). A few authors, including Speigel (6) and Scanlan (7), have noted that training programs should avoid viewing the predictable manifestations of role transition 
as forms of psychopathology. Speigel emphasizes that when these problems "are seen as part of the normal process of learning, rather than as a personal aberration", they can be dealt with in a more effective manner (6).

\section{REVIEW OF SOME OF THE COSTS OF STRESS IN PSYCHIATRIC TRAINING PROGRAMS}

Intrapsychic conflict and regression occurs to some degree in all residents. Merkin and Little described a common, but usually temporary syndrome of neurotic symptoms and psychosomatic disturbances they called the "beginning psychiatry training syndrome" (8). Perhaps more specific to the current discussion, Tischler addressed the ways in which regression relates to professional identity formation (9). He states that one common occurrence is a regression to former modes of professional functioning where some success has been achieved in the past. This primarily presents as "a framework of mental illness solely as a reflection of organic pathology and disturbed behavior as resulting primarily from altered brain functioning". It also can result in a facade of scientific and professional interest "as a barrier between self and patient" (9). Dr. Tischler also discusses how the psychiatric resident searches for external validation of his functioning in these new and varied roles and that commonly this is accompanied by some feelings of insecurity. This combination of insecure feelings and the need for external validation, places the trainee in "a dependent position in relation to role models and validators" (9). Additionally, Tischler notes that "dependent relationships of this type invariably exert a regressive pull, but this regression is usually transitory". He suggests that danger exists only if the "regression is so protracted or the dependency so profound that problems in and about learning become insoluble, role definition is incomplete, professional self-definition is never attempted or professional identity is fused prematurely" (9).

Multiple papers address the issues of psychopathology, training failures, and suicide in psychiatry residents $(1,2,6,8-18)$.

\section{HOW CAN RESIDENTS AND RESIDENCY PROGRAMS FACILITATE ROLE DEVELOPMENT?}

If we assume that one of the primary goals of residency programs is to foster the appropriate professional identity formation of its residents, what techniques are used to deal with these stressors which may interfere with this process? Some common methods include experiential process groups, staff advisors for residents, and the liaison role of the director of residency training. For residents who are displaying overt evidence of impaired performance, increased supervisory time, decreased service workload and individual therapy are often utilized to help the resident improve his functioning.

Other examples of ways to address stress in residency training have 
included Jensen's (19) "Transition to residency seminar" and Gerber's (20) time-limited group process experience. These approaches shared common features in that both were group experiences with the core of the group members being residents in their first year of psychiatric training and both groups used didactic material to address these issues. Jensen presented a journal club format which included discussions of articles related to residency training issues. He concluded that some of the benefits of his approach were: 1) a non-threatening forum (attributed in part to the absence of senior staff) in which residents could discuss their feelings about the residency, and 2) the presence of chief residents and junior staff members benefiting the group by sharing that they had experienced similar problems during their training (19). Gerber reports addressing these issues by "exploring the dynamics of adolescent rebellion" in a shared group experience that included, but theoretically is not lead by, a senior staff member trained in group process. Gerber also discussed group cohesion, identification with the group advisor and universalization of the common experience, as the factors that lead to an enhanced formation of identity as a psychiatrist (20).

Other than Jensen's work very little has been written about how residents themselves could work to foster their own development of professional identity. While active and thoughtful utilization of group process may be one way for residents to approach these issues, a review of the literature reveals a paucity of information on the actual prevalence of resident organizations, temporary or otherwise, within residency training programs or the function such groups may serve. An article written in the early 1970's by residents at the Menninger School of Psychiatry (21) described the existence of a house staff organization and suggested that it "may play some part in the residents personal and professional development", but did not elaborate on how this may be brought about. The article also did not describe what function this organization actually served, except to note that the majority of residents felt that it should "primarily represent their personal interests (salary, benefits, and education) by serving as a liaison with the Menninger School of Psychiatry and only secondarily that it concern itself with social issues and community service" (21).

\section{STRUCTURE OF A PSYCHIATRY RESIDENTS' COUNCIL (PRC)}

The structure of the PRC at Eisenhower Army Medical Center, where the author did his residency training, is provided in the by-Laws that were established by previous resident groups and have been revised by each succeeding year's group. The general structure of these by-laws is included as Table 1 . There are several important reasons why there should be written guidelines for these councils. First, they provide an objective structure as a starting point, and as a continuing reference point when there are conflicts and questions about the councils purpose and function. By-laws also function as a constant to connect each successive academic year, allowing for some modification as needed, but in 


\section{Example of By-laws of a Psychiatry Residents' Council}

I. The name of the organization shall be the Psychiatry Residents' Council (PRC).

II. The voting membership will consist of all psychiatry residents.

III. Goals and Purpose:

a. The PRC will provide a mutual support system for the members.

b. The PRC will promote the professional education and personal growth of the members.

c. The PRC will serve as a forum for resident opinion, for peer sharing and feedback.

d. The PRC will coordinate resident representation to faculty committees.

e. The PRC will influence the selection of new residents, welcome them, and facilitate their orientation.

f. The PRC will provide resident feedback and evaluation of faculty performance and curriculum design.

g. The PRC will plan social functions and promote fellowship among the members.

IV. Roles of Officers

a. President

1. Will conduct PRC meetings as chair-person.

2. Will keep himself informed of the issues of concern to each intergroup of the PRC; and have the authority to act as a representative of the PRC during the interim between meetings.

3. Will serve as representative of the PRC as a whole, to include attendance at pyschiatry departmental meetings.

4. Will hold office for twelve months.

5. Will have authority to appoint committee chair-persons.

6. Shall cast the deciding vote in case of a tie.

b. Vice President/Secretary:

1. Will serve as chair-person of the PRC meetings in the absence of the President.

2. Will work with the President to keep informed of current issues of each intergroup of the PRC.

3. Will hold office for twelve months.

4. May be called upon to act as Chair-person for special purpose groups, e.g., welcoming committees.

5. Will record, publish, and distribute, to residents the minutes of PRC meetings.

6. Will collect and handle monies as directed by the President.

7. Will handle correspondence for the PRC.

c. Removal of officers will be by two-thirds majority of the entire membership.

V. Meetings:

a. The PRC will meet each month at

b. Emergency meetings may be called by the President or Vice-President.

c. A quorum is defined as at least $50 \%$ of the psychiatry residents.

d. A motion will be carried by simple majority.

e. A member must be present in order to have a vote in a meeting.

f. Conduct of the meeting will be under simplified Roberts's Rules of Order.

g. The PRC meetings will be closed meetings, however the chair or a majority vote of the membership may at anytime open the meeting to appropriate outside parties.

VI. Amendments to these By-Laws will be by simple majority 
general giving the council some tradition and continuity from year to year as council leadership and membership changes. Perhaps most importantly they help clarify that responsibility for what the Psychiatry Residents' Council is, and what it does or doesn't do, lies with the residents and not with the staff, the chief, or anyone else in the residency program.

The current PRC at Eisenhower has a PGY-3 serving as the President and a PGY-2 serving as the Vice-President/Secretary. Attendance at the monthly meetings varies from $30 \%$ to $90 \%$ of the residents. Examples of some recent issues have included: 1) curriculum changes, with formation of resident committees to draft and present specific proposals to the faculty, 2) communication problems between residents that are arranging outpatient follow-up for discharged patients and the residents who will provide that follow-up care, 3) discussion of regional APA activities, to provide information on these activities and to encourage resident and staff involvement, 4) revising the system for resident call roster coverage, 5) a meeting with the director of residency training to discuss the JCAH accreditation process, and 6) discussion of various training Fellowship opportunities.

\section{DISCUSSION}

Involvement in a resident's organization with the goal of communication and decision making about residency issues, could be of significant benefit to the development of the resident's professional and personal identity. Possible factors may include: 1) group characteristics of universality, group cohesion and role modeling which could occur despite this being an overtly non-therapeutic group (these benefits may be maximized if not only beginning residents, but rather, all residents are council members), 2) by being titled council, rather than group, and by having a primary task of solving problems within the residency program, the aura of therapy is avoided and more of a "work group" (22) could be maintained, 3) some of the resident's external validation could come from such a group, rather than exclusive dependence on staff for professional validation as noted in Dr.Tischler's paper (9), 4) the transitory and universal nature of the reactions to training stressors can be shared by having more experienced residents be a part of such a group, 5) peer cooperation in identifying, discussing and addressing problems can develop administrative skills and could provide valuable experience in functioning on committees of peers (this may also increase the resident's willingness to become involved in other organizational activities both within the residency and in the community), 6) as individuals are separated throughout the training system on various rotations, the council would provide a forum to enhance resident communication, with each other and with the staff, 7) the difficulty of maintaining a work group focus, in the face of basic assumption group forces (43) (present in this type of group as it is in all groups), will be a central feature of any PRC. Dealing with these group 
forces will be an experiential process, above and beyond the intellectual study of group relations theory, that is essential to psychiatric training.

\section{REFERENCES}

1. Yager J: A survival guide for psychiatric residents. Arch of Gen Psych vol. 30: 494-500, 1974

2. Graves JS: Becoming a psychiatrist, or adolescence revisited. Psych Annals 6:41, 191-196, 1976

3. Garfinkel PE, Waring EM: Personality, interests, and emotional disturbance in psychiatric residents. Am J Psych 138:51-55, 1981

4. Hales RE, Borus JF, Privitera CR: Unique characteristics of army psychiatry residency programs, in W. W. Menninger, (Ed.) Military Psychiatry: Learning from experience. The Menninger Foundation 38-48, 1987

5. Levinson DJ, Darrow CN, Klein MH, McKee B.: The seasons of a man's life. New York, Ballantine Books, 1978

6. Spiegel D, Grunebaum H: Training versus treating the psychiatric resident. Am J Psychother 31:618-625, 1977

7. Scanlan JM: Physician to Student: The crisis of psychiatric residency training. Am J Psych 128:1107-1111, 1972

8. Merklin L Jr, Little RB: Beginning psychiatry training syndrome. Am J Psych 124:193-197, 1967

9. Tischler GL: The transition into residency. Am J Psych 128:1103-1106, 1972

10. Campbell HD: The prevalence and ramifications of psychopathology in psychiatric residents: An overview. Am J Psych 139:1405-1411, 1982

11. Garetz F, Roths O, Morse R: The disturbed and the disturbing psychiatric resident. Arch Gen Psych 33:446-450, 1975

12. Waring EM: A preventive approach to emotional illness in psychiatric residents. Psych Quarterly vol. 49: 303-315, 1977

13. Jensen PS: Barriers to working with impaired trainees: A resident's viewpoint. Psych Quarterly 55:268-271, 1983

14. Kelly WA Jr: Suicide and psychiatric education. Am J Psych 130:463-468, 1973

15. Pasnau RO, Russell AT: Psychiatric resident suicide: An analysis of five cases. Am J Psych 132:402-406, 1975

16. Russell AT, Pasnau RO, Taintor ZC: Emotional problems of residents in psychiatry. Am J Psych 132:402-406, 1975

17. Russell AT, Pasnau RO, Taintor ZC: The emotionally disturbed psychiatric resident. Am J Psych 134:59-62, 1977

18. Yager J, Pasnau RO: The educational objectives of a psychiatric residency program. Am J Psych 133:217-220, 1976

19. Jensen PS: The transition to residency seminar. J Psych Educ vol. 7: 261-265, 1985

20. Gerber JP, Strassman, HD, Pappadis, T.: Psychiatric residency identity crisis: resolution through group process. J Psych Educ vol. (1), Spring/Summer, 1977

21. Fried FE, Doherty EG, Coyne L: Psychiatric residents: A survey of training needs, satisfactions, and social attitudes. Am J Psych 130:1342-1345, 1973

22. Rioch M: The work of Wilfred Bion on groups. Psych 33:56, 1970 
23. Blackwell B., Gutmann, MC, Jewell, KE: Role adoption in residency training. Gen Hosp Psych 6:280-288, 1984

24. Bowden CL, Humphrey FJ, Thompson MG: Priorities in psychiatric residency training. Am J Psych 137:1243-1246, 1980

25. Bowden CL, Sledge WH, Humphrey, et al: A survey of training directors and residents. Am J Psych 140:1352-1355, 1983

26. Brockman DD, Marengo J: Outcome study of psychiatric residents of the University of Illinois Neuropsychiatric Institute (1959-1972). J Psych Educ 5:20-21, 1981

27. Daniels RS, Abraham AS, Garcia R, Wilkinson C.: Characteristics of psychiatric residency programs and quality of education. Am J Psych, March 1977, Supplement; 134:7-10

28. Fleckles CS: The making of a psychiatrist: The resident's view of the process of his professional development. Am J Psych 128:101-104, 1972

29. Friedmann CT, Krout BM: A survival tip for small residency training programs. J Psych Educ vol. 3, 226-230, 1979

30. Garrard J, Berg JK: Psychosocial support of the residents in psychiatric programs: A national survey. J Psych Educ 7:251-261, 1983

31. Ham, CH, Rothstein, W.: Evaluating a psychiatric training program. J Psych Educ vol. 3: 91-98, 1979

32. Haberman S, Laury G, Mailick S, Miller H: A systems approach to management training for mental health professionals. Psych Quarterly, vol. 49: 291-302, 1977

33. Kardener SH, Fuller M, Mensh I, et al: The trainees viewpoint of psychiatric residency. Am J Psych 126:1132-1138, 1970

34. Pasnau RO, Bayley SJ: Personality changes in the first year of psychiatric residency training. Am J Psych 128:79-83, 1971

35. Riggs BC: Psychiatric Education: A general systems approach. J Psych Educ vol. 1(1): 85-92, 1977

36. Siegel B, Donnelly JC: Enriching personal and professional development: The experience of a Support Group for interns. J Med Educ 53:908-914, 1978

37. Skodal AE, Maxem JS: Role satisfaction among psychiatric residents. Comp Psych 22(2):174-178, 1981

38. Taintor Z: Group sensitivity training for psychiatric residents. J Psych Educ vol. 1: 93-99, 1977

39. Taintor Z, Murphy M, Seiden A, Val E: Psychiatric residency training: Relationships and value development. Am J Psych 140:778-786, 1978

40. Taintor Z, Murphy M, Pearson M: Stress and growth factors in psychiatric residency training. Psych Quarterly, 53:162-169, 1981

41. Taylor RL, Torrey EF: The self-education of psychiatric residents. Am J Psych 128:1116-1121, 1972

42. Ungerleider JT: That most difficult year. Am J Psych 122:542-545, 1965

43. Rice AK: Learning for Leadership. Tavistock Clinic, 1967 